\title{
Autologous Fat Graft
}

National Cancer Institute

\section{Source}

National Cancer Institute. Autologous Fat Graft. NCI Thesaurus. Code C126279.

The transfer of an individual's own body fat from one location to another. 